\title{
Patient-Oriented Treatment for Urticaria: A Three-Step Approach with Informational/Instructional Sheets
}

\author{
Craig G. Burkhart \\ University of Toledo College of Medicine, 5600 Monroe Street, Suite 106B, Sylvania, Ohio 43560, USA
}

\begin{abstract}
Urticaria is a common dermatosis characterized by spontaneous recurrent bouts of hives. A common belief is that the tedious search for an underlying cause of spontaneous urticaria is fruitless, and even when successful an appropriately dealt with, is not necessarily followed by complete resolution of symptoms. In contrast, urticaria has a great impact on patients' quality of life. These patients suffer considerable loss of energy, sleep disturbance, and emotional upset. Urticaria remains a big problem in term of etiology, pathogenetic mechanism, and pharmacologic treatment. Whereas textbooks and reviews on the topic of urticaria devote limited space to investigations and optional trial therapies for the entity, this article is devoted to the subject. A three-step template for the treatment of urticaria is offered which may prove helpful for you and your patients.
\end{abstract}

Urticaria is a disease known since antiquity with even Hippocrates suggesting that it was a distinct entity. Although there is increasing understanding of the mechanisms involved with its pathogenesis, the ultimate treatment still eludes clinicians and researchers. There is a spectrum of clinical manifestations which can manifest as urticaria, due to the great heterogeneity of different subtypes. Urticaria is often classified by the various mechanisms which can elicit clinical disease. The major subtypes are spontaneous urticaria, physical urticaria, and contact urticaria. Spontaneous urticaria is usually further classified as acute or chronic, depending on whether wheals occur repeatedly for less or more than 6 weeks.

By definition, urticaria is characterized by the rapid appearance of itchy wheals which have central swelling of variable size surrounded by a reflex erythema. Such lesions are self-limiting and fleeting in nature, lasting up to 24 hours in duration.

A common belief is that the tedious search for an underlying cause of spontaneous urticaria is often fruitless, and even when successful an appropriately dealt with, is not necessarily followed by complete resolution of symptoms [1]. The medical literature suggests that extensive panel of screening investigations add little to the detection of underlying disorders [2]. Of note, a fairly recent review on the topic of urticaria in a major dermatological journal spent only one paragraph only on investigations for the entity [3]. To little surprise, many physicians do not energetically nor enthusiastically pursue remedial measures for such patients.

In contrast, urticaria has a great impact on patients' quality of life. These patients suffer considerable loss of energy, sleep disturbance, and emotional upset $[4,5]$. Urticarial patients experience more limitations due to physical and emotional problems that patients suffering with respiratory

*Address correspondence to this author at the University of Toledo College of Medicine, 5600 Monroe Street, Suite 106B, Sylvania, Ohio 43560, USA; E-mail: cgbakb@aol.com allergies or vitiligo [6,7]. For urticarial patients and their physicians, I offer a template to hopefully spur one's detective work with these patients.

Acute urticaria is prevalent with $25 \%$ of the populace experiencing this condition during one's lifetime. However, the cause is often hard to determine. A detailed history of the circumstances at the onset of the eruption can be most important in determining possible etiological triggers. The history should include:

- $\quad$ Detailed review of all recently administered medications, herbal, or supplements.

- $\quad$ Food exposure, including ingestion, inhalation, and contact.

- Physical triggers such as cold, exercise, heat, sweating, sun, pressure.

- Infectious processes including possible tooth pain, respiratory virus, viral hepatitis.

- $\quad$ Occupational exposure to allergens or irritants.

- $\quad$ Recent insect sting.

- $\quad$ Allergen exposure by inhalation.

- A complete review of systems to include systemic diseases such as autoimmune, connective tissue, and lymphoproliferative disorders.

Although two-thirds of patients attribute acute urticaria to food [8], the medical experts have divergent views, with reports from $0 \%$ to $92 \%$ being reported $[9,10]$. Drugs, viral infections, and recent insect sting are other common causes of this condition. Additionally exposure to animals or molds via inhalation or physical contact with pollens, animal dander, and mold spores can be culprits.

The prevalence of chronic urticaria is difficult to assess given the paucity of cross-sectional studies. There are innumerable possible causes of chronic urticaria and the etiology remains unidentified in more that $80 \%$ of reported cases. As with acute urticaria, a complete history and physical exami- 
nation may elicit identifiable triggers, including physical causes such as pressure, cold, or heat. One should also check for dermatographism, an immediate wheal-and-flare response on stroking the skin. Again, systemic causes should be considered during the history. For example, if any individual lesion lasts for over 24 hours, the diagnosis of urticarial vasculitis should be considered, and one should entertain the need for a confirmatory skin biopsy. In terms of possible food etiologies, double-blinded, placebo-controlled food challenge studies are rare with this condition; this makes it difficult to assess relevance and need of elimination diets in clinical practice. Indeed, improvement by dietary alterations with chronic urticaria have been reported to be as high as over $93 \%$ and as low as $2 \%$ in different studies [11, 12]. Viral, bacterial, and parasitic infections can be associated with chronic urticaria. Drug exposure is a common culprit and pharmaceuticals, including over-the-counter medications, vitamins, "naturopathic" supplements and other herbal remedies need to be assessed. Additional causes include hypersensitivity of a drug, anti-IgE receptor autoantibodies, thyroid autoantibodies, gastritis, bowel inflammation, lupus, and neoplasia. Even environmental allergens such as house dust mite, fungi, pollen, trees, pets or a chemical present in a toy or used in a hobby should be considered. Psychological factors and stress are both a consequence and a triggering cofactor.

For classification purposes, physical urticaria can be further divided into categories of dermographism, delayed pressure, cold contact, heat contact, solar, and vibratory. Cholinergic, adrenergic, contact, vasculitic, and aquagenic urticarias are distinct rare cause of this disease entity. These forms of urticaria can be distinguished by the precipitating event and other aspects of clinical presentation, and specific measures can be instituted in some of these disease states. One would not necessarily follow the instructional maneuvers suggested below in such individuals.

The ideal treatment is the identification and avoidance of the specific cause and thereby improve both physical symptoms and patients' quality of life [13]. However, very often no trigger factors can be identified from history or physical examination. Unfortunately, pharmacological treatment is palliative at best. Now most physicians will institute an $\mathrm{H}_{1}$ antihistamine with non- or low-sedating antihistamines for daily use which may offer some symptomatic relief. Although some progress has been made at improving symptomatic control of urticaria, further research and discovery are necessary before there can be an effective impact on the underlying course and natural history of this condition [14]. Of note, there is a wide disparity as to what additional step(s) an individual physician will follow after that. The remainder of this paper will discuss how one physician approaches this situation.

In terms of clinical management of urticaria, the basic tenets are avoidance or elimination of possible eliciting factors, inhibition of mast cell release, and therapy of target tissues of mast cell mediators. To this, I add an additional method, namely trial and error of therapies directed at possible latent infections, as well as having a liberal view of potential causes which can be eliminated.

Inasmuch as most patients seek medical attention within the first week of hives, whether the patient can be defined as acute or chronic is dependent upon whether one is the first (second, third, or fourth) physician to attend to the patient's complaints. Consequently, I use the same instructional sheets in a monthly step-wise process regardless of the date of onset of the condition. These sheets are readable and selfexplanatory.

Regarding avoidance of eliciting stimuli, elimination of provocative environmental, drug, or dietary factor is the simplest, most direct, and potentially most efficacious therapy. Indeed, all possible potential causes should be eliminated. I suggest specific measures even though an exact diagnosis has not necessarily been proven. For example, any suspected drug is omitted entirely or substituted by another class of drug. Despite not proving IgE-mediated food allergy, dietary maneuvers are instituted in my practice. Two elimination diets are routinely tried, namely a penicillin-free diet and one that eliminates tartrazine and aspirin. For literature support for these dietary eliminations, I offer one study in which there was $57 \%$ of improvement by eliminating hidden sources of penicillin [15]. Also, while $20 \%$ to $40 \%$ of patients with chronic urticaria exacerbated with administration with aspirin and other salicylates [16-18]. the elimination of aspirin totally eliminated urticaria in $6 \%$ of patients [18].

The laboratory work-up of spontaneous urticaria is varied. In my practice, a laboratory screen for underlying disease is common practice on the first visit. The testing includes a $\mathrm{CBC}$, erythrocyte sedimetntation rate, urinalysis, liver, and kidney function to evaluate for systemic etiologies of chronic urticaria.

If little clinical improvement is achieved by this threestep approach, a patient is given the option of pursuing an allergist for evaluation of autoimmune triggers including the presence of antithyroid antibodies and antibodies against the IgE receptor. Although I have found little use for intradermal, scratch and patch testing, radioallergosorbent (RAST) and blood cellular allergen stimulation tests, allergists more often utilize these studies.

As urticaria affects the quality of life, patients expect concerned physicians with some basic thoughts for treatment to offer them. Although an individual approach is perfect when the source of the problem is obvious, more commonly, the cause of urticaria is unclear and various disease measures need to be initiated or tried. This template for the treatment of urticaria may prove helpful for your patients, and urticaria patients truly appreciate physicians who make an extra effort to solve their itchy dilemma.

\section{Craig G. Burkhart, MD, MPH}

\author{
5600 Monroe Street, Suite 106B, Sylvania, \\ Ohio 43560, USA
}

\section{INFORMATION ON URTICARIA}

Urticaria, or hives, is a common disorder characterized by itching, scratching, and burning wheals. At least $20 \%$ of people will develop some form of hives in his/her life. It is usually caused by an allergic (immune) reaction to a food, drug, or infection. Stress, scratching, and heat make hives 
worse, but do not by themselves cause hives. The condition is intermittent and outbreaks typically clear up without any treatment.

The cause of hives is often hard to determine. The possibilities of specific causes are numerous (anything can potentially cause hives). If one's triggers can be identified, then outbreaks can be managed by limiting one's exposure to these factors. The most common cause of hives is drugs. In all cases of hives, it is wise to avoid all unnecessary prescription and over-the-counter medications, as permitted and under the direction of your primary care physician. The most common drug causing hives are antibiotics. If you have taken an antibiotic within 6 weeks of the onset of hives, this would be the most likely culprit. Other common causes of hives include infection, dental abscesses, bites, and dietary factors.

Hives lasting over 6 weeks is considered chronic urticaria. This is because one inciting factor (i.e. an oral medication, a flu shot) can cause the immune system to continue reacting for as long as 6 weeks after its occurrence. Thus, if hives last longer than 6 weeks, then one is looking at some factor that is on-going. In cases of chronic hives, I often ask for blood tests to be performed looking for some in-sight as to a cause of your problem. Blood tests may direct us to a cause, but there is no blood test that will tell us specifically what is definitely causing your hives. I will call you if the blood tests show an abnormality. Make sure that I write the name of your primary physician on the blood request, so that he/she also gets a copy of the results.

If you are on other medications, it is often helpful for your pharmacist to review all your medications and have $\mathrm{him} / \mathrm{her}$ perform a computerized check to see if any of your medications are listed as a cause of urticaria. Also, you should consider stopping all herbal, over-the-counter, and recreational drugs for a month.

For hives in which no obvious culprit is known, I will give you an additional sheet for substitutions in your diet. Such diet substitutions work in a high enough percentage to justify its trial. Of note, it takes 4 weeks of elimination of these substances from the diet before one can state that it is not the cause of the problem.

Urticaria can be very difficult to treat. Obviously, identifying and eliminating the cause is the preferred therapy. One should avoid stress, scratching, and heat to the skin, as these will aggravate hives. Medical treatments for urticaria are less than perfect. I will provide you with oral antihistamines which should be taken until the hives have cleared, and which hopefully will at least lessen the severity attacks. Other drugs, if needed, will be considered on your return visit in four weeks...but first we need to try this treatment outlined in the sheet. Oral corticosteroids only give temporary help and do not cure the problem; they are reserved for patients with laryngeal edema or systemic symptoms of anaphylaxis in my practice.

With resistant cases, I suggest being your own detective and look up 'urticaria' in books or the internet to see if you can help figure out the cause in your case. Two search engine sites that might be worth a look are www.emedicine.com and www.WebMD. If you find something of note, bring the information to me on your return visit. P.S. I have a three step treatment approach to urticaria that has a high success rate......so don't panic if you don't at first succeed, that means I'll see you in 4 weeks for step 2 .

\section{Craig G. Burkhart, MD, MPH}

\author{
5600 Monroe Street, Suite 106B, Sylvania, \\ Ohio 43560, USA
}

\section{INFORMATION ON URTICARIA (SECOND VISIT)}

With urticaria, the cause is often hard to determine, as you have become aware. Of course if we found some leads to pursue on the history or blood testing from the first visit, we will pursue them.

On this visit I will do four additional treatments in the hopes that one will cure your hives. First, I will add Zantac $150 \mathrm{mg}$ twice a day to the therapy. As you may know, hives is caused by the breakdown of mast cells which lead to the release of histamine. Histamine affects the blood vessels causing the welts that we all know is hives. Zantac is a different type of antihistamine from the one given on your previous visit. Zantac is also a drug that blocks histamine from getting to the blood vessels. In this case, the drug is an inhibitor of histamine at the level of the histamine H-2 receptors. Side effects to Zantac are not common. You should be given the package insert from the pharmacist when you pick up the drug and you can familiarize yourself with the drug. Certainly call my office if you notice any problems taking the drug. Side effects reported (though rare) include headache, dizziness, change in heart beat, and abdominal discomfort. I will be monitoring the liver enzymes and blood counts if we stay on the drug for any duration.

Secondly, I will add an antibiotic, namely minocycline $100 \mathrm{mg}$ a day to the therapy. This is in case there is a nidus of bacterial infection that might be causing the problem, or an imbalance of bacteria someplace in the body (an altered biofilm), and that by taking an all-purpose bacteria, we can circumvent that problem. This drug is absorbed over $90 \%$ with meals, and one can disregard the possible pharmacist's suggestion that you have to take this drug in-between meals. Also, sun sensitivity is $1 \%$ (which is not much at all) and any pharmacist suggestion that you have to avoid sun can also be disregarded.

Third, I will give you the other substitution diet which I find most helpful in urticarial patients. Such diet substitutions work in a high enough percentage to justify its trial. Of note, it takes 4 weeks of elimination of these substances from the diet before one can state that it is not the cause of the problem.

Fourth, I will also suggest taking Vermox 1 tablet for two days. This drug eliminates another possible cause of urticaria, that being pinworms and other gut parasites. The drug is not absorbed and therefore is basically without any potential side effects. Although the American media doesn't talk about pinworms, a British study found $50 \%$ of people infested. One can have pinworms and have no symptoms of groin itch. Anyway, in my mind, this treatment is well worth a try. 
If you have found anything else from your investigations of urticaria by the internet or by books, please direct your thoughts to me.

\section{Craig G. Burkhart, MD, MPH}

\author{
5600 Monroe Street, Suite 106B, Sylvania, \\ Ohio 43560, USA
}

\section{INFORMATION ON URTICARIA (THIRD VISIT)}

A third visit for hives means that we have not been able to correct the problem with my therapeutic approach....so far. On this visit, I will add four additional treatments in the hopes that one will cure your hives.

First, it is still very possible that your hives still have a dietary cause. Allergists might offer laboratory testing in this search for food-induced urticaria, such as targeted foodspecific prick tests, and serum IgE-specific assays, also referred the radioallergosorbent test (RAST)....but I have not found such tests helpful (not mentioning expensive). I still prefer a 'trial and error' approach in seeking a possible dietary etiology to this problem. At this point you have tried two diets which I provided you with hand-outs. At this point, you can try various elimination diets which you can find over the internet \{type into www.google.com <elimination diets $>$ \} or in textbooks such as Janice Vickerstaff Joneja's Dealing with Food Allergies. For example, there are numerous potential elimination diets with dietary management for such items such as eggs, wheat and grain, soy, peanuts, nut and seeds, fish, benzoate, sulfites, and nitrates. If you would rather just have me provide you with a short list of foods that are often considered highly allergenic, I can do that. The foods to avoid include beans, peanuts, tree nuts, mustard, nuts, ginger, milk, cheese, wheat, egg, shrimp, shellfish, soy, beer, and wine. Also eliminate cold cures, over-the-counter drugs, and herbal remedies, if you haven't already eliminated them.

Secondly, I will initiate Asacol two $400 \mathrm{mg}$ tablets three times a day. This drug is an anti-inflammatory agent which I have found helpful in difficult cases. You should be given the package insert from the pharmacist, and you will see that it is a very safe drug....but please inform me if you have any known renal dysfunction or history of kidney disease as this would be an indication for not receiving this medication. The drug is well-tolerated and the overall incidence of adverse events is comparable to placebo (sugar pills). The most common side effects would be head ache, abdominal pain, and diarrhea. Certainly call my office if you notice any problems taking the drug. Also, we will take baseline blood tests if we opt to take the drug for any duration over a month.

Third, I will initiate Singulair $10 \mathrm{mg}$ once a day. This drug is what is called a leukotriene receptor antagonist which means that it blocks some of the substances which cause hives in some patients. It is common drug used for asthma and has very few side effects. Nevertheless, you should ask the pharmacist for a package insert and be vigil in case you develop any problems with this drug.
Fourth, we will try Stromectol, taken on day 1 and day 8 . Stromectol (the generic name is ivermectin) is a drug commonly used for bugs, scabies, and parasites. Stromectol is extremely safe except for fetuses. Thus, we will not take this drug only if you are pregnant or breastfeeding. The drug dosing is adjusted for weight.

Dosage Guidelines for Stromectol

\begin{tabular}{|c|c|}
\hline Body Weight (in Pounds) & \# of Tablets Taken on Day $\mathbf{1}$ and Day 8 \\
\hline \hline $30-49$ & 1 \\
\hline $50-74$ & 2 \\
\hline $75-99$ & 3 \\
\hline $100-124$ & 4 \\
\hline $125-149$ & 5 \\
\hline $150-175$ & 6 \\
\hline $176-200$ & 7 \\
\hline $200-225$ & 8 \\
\hline $226-250$ & 9 (and so forth) \\
\hline
\end{tabular}

All tablets are 3-mg tablets presently.

Lastly, keep reading on urticaria, as I am. If you still have problems, I will welcome you back in 4 weeks.

\section{Craig G. Burkhart, MD, MPH}

\author{
5600 Monroe Street, Suite 106B, Sylvania, \\ Ohio 43560, USA
}

\section{PENICILLIN AND MOLD-CONTROLLED DIET}

Certain foods have been implicated in causing urticaria. Elimination diets occasionally are occasionally curative for this condition. It takes a full four weeks to assess if any diet is helpful.

Penicillin in food can cause urticaria, with reports as high as $8 \%$ of patients in one study. This diet is intended to eliminate penicillin and molds. The contamination of milk occurs when animals are treated with penicillin. Milk and all dairy products are to be avoided. In terms of mold, food sources include mold foods (i.e. mushrooms), mold-containing foods (i.e. cheese, sour cream, buttermilk, bacon), and moldacquiring foods (i.e. jams, jellies, teas, spices). While on this diet, read product labels carefully.

Additionally, cow's milk contains over 25 different molecules (including casein and whey) which have potential of eliciting an allergic reaction. Milk is repeatedly ranked among the top eight offenders for food allergy. Thus, this diet also gauges whether milk allergy might be the cause of your hives.

Please adhere to the diet for a four-week trial. If the diet is successful and is to be continued for an extended period, a calcium supplement may be indicated. Please check with your primary care physician or a dietitian on this matter. 
Foods to Avoid and Foods Allowed in the Penicillin- and Mold-Free Diet

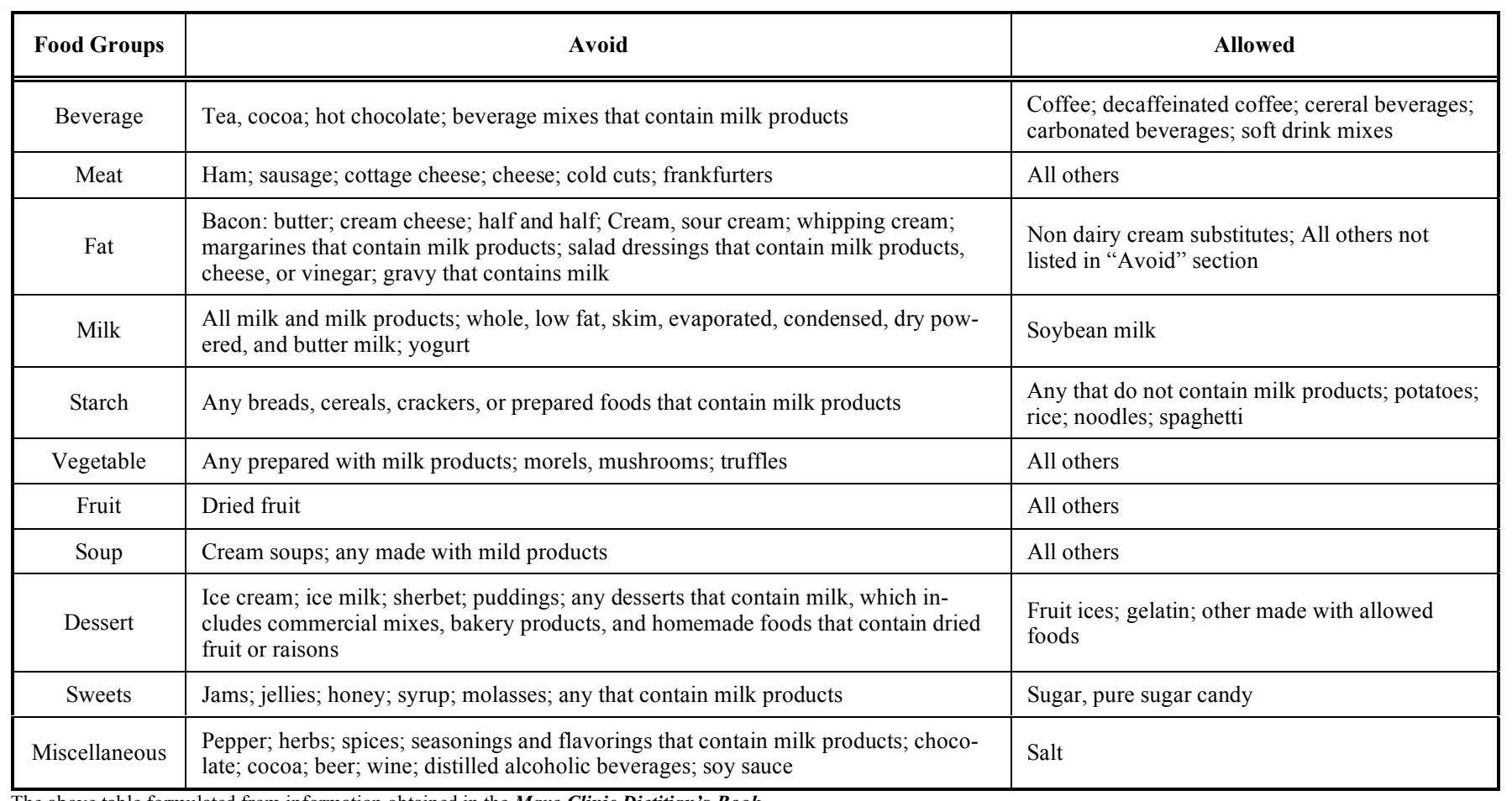

The above table formulated from information obtained in the Mayo Clinic Dietitian's Book.

\section{Craig G. Burkhart, MD, MPH}

\author{
5600 Monroe Street, Suite 106B, Sylvania, \\ Ohio 43560, USA
}

\section{LOW SALICYLATE (ASPIRIN-FREE) AND TAR- TRAZINE-FREE DIET}

Diets that restrict salicylates and tartrazine have been very beneficial in some patients with urticaria. I suggest elimination of both products from the diet because so many individuals are sensitive to both agents. In cases of hives in which the cause is often not obvious, I suggest sticking to this diet for a full four weeks before conceding that it is not useful in your case.

Salicylates occur naturally in many foods, including fruit, vegetables, herbs, spices, nuts, and seeds. It is also in wintergreen or mint flavorings. Also, besides following the diet, you are asked also to avoid aspirin and any over-the-counter products with acetylsalicylic acid in it. Now, the level of salicylate acid appears to the determining factor in salicylate sensitivity. This is important as one cannot totally eliminate salicylates from one's diet. Thus, this diet is avoiding foods with higher levels of salicylates.

Tartrazine is also referred to as FD\&C Yellow No. 5, and is a certified coloring dye used in foods, drugs, and cosmetics. Because of the occasion adverse reactions to tartrazine, food manufacturers are required to give the specific name of this artificial coloring on the label. Patients need to check product ingredient labels for the words "tartrazine", "FD\&C yellow No. 5", or "Yellow \#5." People on a this diet must avoid (1) any food or medication listing tartrazine as an additive, (2) any food described as containing color or artificial color unless it is specifically labeled tartrazine-free. This is particularly important for medications, (you may have to check with your pharmacist on this point). While on the diet, a product is only acceptable if it has been established that it does not contain tartrazine.

For those who like medical reasons, salicylates affect the cyclo-oxygenase pathway of arachidonic acid metabolism and thus reduce the production of certain prostaglandins. Indirectly they also affect production of leukotrienes. Tartrazine can affect release of histamine from mast cells.

If the diet improves the urticaria and one plans on continuing the diet for an extended period, then one must realize that this diet limits one's fruit and vegetables. In this case, a multiple vitamin supplement (free of salicylates and tartrazine) is recommended. Additionally, one needs to notify one's primary care physician in case he is concerned about any possible nutritional inadequacies.

If you have questions about these particular diets, I would suggest the internet or books such as Janice Vickerstaff Joneja's Dealing with Food Allergies. You will find some differences with different dietitians in terms of what specific foods should be avoided, so my table should function as a guideline only (not gospel).

Food sources of salicylates and tartrazine are listed separately to the diet can be adjusted to meet one's particular needs. If one finds the diet too constrictive, one could be one a tartrazine-free diet for 4 weeks, followed by a salicylatefree diet the following month. 
Food Sources of Tartrazine and Salicylates

\begin{tabular}{|c|c|c|c|}
\hline Food Groups & May Contain Tartrazine* & Contains Salicylates $(>.4 \mathrm{mg} / \mathbf{1 0 0 g})$ & Allowed Foods \\
\hline Beverages & $\begin{array}{l}\text { Carbonated beverages, soft drinks and } \\
\text { soft drink mixes, orange drinks }\end{array}$ & Tea, root beer, birch beer & $\begin{array}{l}\text { Coffee, decaffeinated coffee, cereal } \\
\text { beverage }\end{array}$ \\
\hline Meat & $\begin{array}{l}\text { Sausage, frankfurters, cheese-flavored } \\
\text { foods }\end{array}$ & Corned beef, meat processed with vinegar & All other meats, fish, fowl, eggs, cheese \\
\hline Fat & Non-dairy cream & $\begin{array}{l}\text { Salad dressing, mayonnaise, olives, avocado, } \\
\text { almonds, peanuts, cashews, sunflower seeds, } \\
\text { Brazil nuts, Macadamia nuts, pistachio nuts }\end{array}$ & $\begin{array}{l}\text { Butter, margarine, vegetable oil, cream } \\
\text { products, other nuts and fats not listed } \\
\text { in other columns }\end{array}$ \\
\hline Milk & Yogurt, hot chocolate, and cocoa mixes & Fruited yogurt & Milk, cheeses \\
\hline Starch & $\begin{array}{l}\text { Ready-to-eat cereals, variety crackers, } \\
\text { noodles, commercial mixes including } \\
\text { macaroni and cheese }\end{array}$ & Yellow corn meal & $\begin{array}{l}\text { Bread, spaghetti, macaroni, rice, most } \\
\text { commercially prepared rolls and breads, } \\
\text { potato, barley, oats, rye and wheat } \\
\text { flours }\end{array}$ \\
\hline Vegetable & & $\begin{array}{l}\text { Alfalfa sprouts, broccoli, endive, bean sprouts, } \\
\text { cucumbers, green bell peppers, tomatoes } \\
\text { (canned), pimentos, okra, parsnip, pumpkin, } \\
\text { sweet potato, spinach, squash, zucchini, water- } \\
\text { cress, asparagus (fresh), water chestnuts }\end{array}$ & $\begin{array}{l}\text { Asparagus (canned), bean spouts, Brus- } \\
\text { sels sprouts,cabbage,carrots, celery, } \\
\text { cauliflower, corn, lentis, lettuce, green } \\
\text { peas, spilt peas, chickpeas, onions, } \\
\text { potato (white), spinach (frozen), tomato } \\
\text { (fresh), tomato juice, mushrooms } \\
\text { (fresh), turnip }\end{array}$ \\
\hline Fruit & & $\begin{array}{l}\text { Apricots, blackberries, boysenberries, cherries, } \\
\text { currants, gooseberries, prunes, huckleberries, } \\
\text { maraschino cherries, grapes, melon, nectarines, } \\
\text { peaches, raisins, raspberries, blueberries, dates, } \\
\text { cranberries, grapefruit, loganberries, oranges, } \\
\text { pineapple, strawberries }\end{array}$ & $\begin{array}{l}\text { Apple, apple juice,apricot nectar, ba- } \\
\text { nana, figs (fresh and canned), light } \\
\text { seedless grapes (canned), kiwi, lemon, } \\
\text { mango, peach nectar, pear, persimmon, } \\
\text { red plums, pineapple juice, rhubarb, } \\
\text { pomegranate }\end{array}$ \\
\hline Soup & Commercial soups and soup mixes & & All made from allowed foods \\
\hline Dessert & $\begin{array}{l}\text { Gelatin, sherbet, ice milk, ice cream, fruit } \\
\text { ice, commercially prepared desserts and } \\
\text { mixes including cakes, frostings, pud- } \\
\text { dings, and gingerbread }\end{array}$ & & All other made from allowed foods \\
\hline Sweets & $\begin{array}{l}\text { Commercially prepared jam, jelly, and } \\
\text { candy; any colored yellow, orange, pink, } \\
\text { green, or brown chewing gum }\end{array}$ & $\begin{array}{l}\text { Honey, licorice; any mint, anise or wintergreen } \\
\text { flavored }\end{array}$ & Sugar, syrup, molasses, all others \\
\hline Miscellaneous & $\begin{array}{l}\text { Cocoa and hot chocolate mixes, flavoring } \\
\text { extracts }\end{array}$ & $\begin{array}{l}\text { Pickles, catsup, tartar sause, beer, wine, Ta- } \\
\text { basco sauce, cider vinegar, wine vinegar, dis- } \\
\text { tilled alcoholic beverages (except vodka and } \\
\text { gin), curry, dill powder, paprika, thyme, mus- } \\
\text { tard powder, garam masala, oregano, tumeric, } \\
\text { other herbs and spices contribute significant } \\
\text { amounts of salicylates to the diet if eaten in } \\
\text { unusually large quantities }\end{array}$ & $\begin{array}{l}\text { Salt, pepper, distilled white vinegar, } \\
\text { cocoa powder, pure chocolate, soy } \\
\text { sauce, garlic (fresh), parsley (fresh), } \\
\text { coriander (fresh), gin, vodka, whiskey }\end{array}$ \\
\hline
\end{tabular}

*These foods are likely to contain tartrazine. If the manufacturer states that a specific brand does not contain tartrazine or FD\&C Yellow No. 5, it may be used. This information is available from the product ingredient label. 


\section{REFERENCES}

[1] Nettis E, Pannofino A, D’Aprile C, Ferrannini A, Tursi A. Clinical and aetiological aspects in urticaria and angio-oedema. Br J Dermatol 2003; 148: 501-6.

[2] Kozel MMA, Mekkes JR, Bossuyt PMM, Bos JD. The effectiveness of a history-based diagnostic approach in chronic urticaria and angioedema. Arch Dermatol 1998; 134: 1575-80.

[3] Grattan CEH, Sabroe RA, Greaves MW. Chronic urticaria. J Amer Acad Dermatol 2002; 46: 645-57.

[4] Staubach P, Eckhardt-Henn A, Dechene M, et al. Quality of life in patients with chronic urticaria is differentially impaired and determined by psychiatric comorbidity. Br J Dermatol 2006; 154: 294-8.

[5] O'Donnell BF, Lawlor F, Simpson J. The impact of chronic urticaria on the quality of life. Br J Dermatol 1997; 136: 197-201.

[6] Baiardini I, Giardini A, Pasquali M. Quality of life and patients' satisfaction in chronic urticaria and respiratory asthma. Allergy 2003; 58: 621-3.

[7] Poon E, Seed PT, Greaves MW. The extent and nature of disability in different urticaria conditions. Br J Dermatol 1999; 140: 667-71.

[8] Zuberbier T, Iffander J, Semmler C, Czarnetzki BM. Acute urticaria: clinical aspects and therapeutical responsiveness. Acta Derm Venereol 1996; 76: 295-7.

[9] Aoki T, Kojima M, Horiko T. Acute urticaria: history and natural course of fifty patients. J Dermatol 1995; 21: 73-7.
[10] Legrain V, Taieb A, Sage T, Maleville J. Urticaria in infants: a study in forty patients. Pediatr Dermatol 1990; 7: 101-7.

[11] Pastorello EA. Evaluation new tests for the diagnosis of food allergy. Allergy 1996; 50: 289-91.

[12] Genton C, Frei PC, Pecoud A. Value of oral provocation tests to aspirin and food additives in routine investigation of asthma and chronic urticaria. J Allergy Clin Immunol 1985; 76: 40-5.

[13] Fromer L. Treatment options for the relief of chronic idiopathic urticaria. South Med J 2008; 101: 186-192.

[14] Dibbern DA Jr. Urticaria: selected highlights and recent advances. Med Clinics N Am 2006; 90: 187-209.

[15] Poljacki M, Jovanovic M, Duran V, Tasic S, Suboic M. Chronic urticaria caused by penicillin: results of monitoring case of acute penicillin urticaria which developed into chronic urticaria. Med Pregl 1995; 48: 108-110.

[16] Warin RP, Smith RJ. Chronic urticaria: investigations with patch and challenge tests. Contact Dermatitis 1982; 8: 117-21.

[17] Juhlin L. Intolerance to food and drug additives. In: Handbook of Experimental Pharmacology (deWeck AL, Bundgaard H, eds). Berlin: Springer Verlag, 1983; 63: 643.

[18] Stevenson DD, Simon RA. Sensitivity to aspirin and nonsteroidal anti-inflammatory drugs. In: Allergy: Principles and Practice (Middleton E, Reed CE, Ellis EF, Adkinson NF, Yunginger JW, Busse WW, eds). St. Louis, MO: CV Mosby, 1993: 1752-3.

(C) Craig G. Burkhart; Licensee Bentham Open.

This is an open access article distributed under the terms of the Creative Commons Attribution License (http://creativecommons.org/license/by/2.5/), which permits unrestrictive use, distribution, and reproduction in any medium, provided the original work is properly cited. 